\title{
EphB2 stem-related and EphA2 progression-related miRNA-based networks in progressive stages of CRC evolution: clinical significance and potential miRNA drivers
}

Mariangela De Robertis ${ }^{1,2^{*}}$, Tommaso Mazza ${ }^{3}$, Caterina Fusilli ${ }^{3}$, Luisa Loiacono ${ }^{1,4}$, Maria Luana Poeta ${ }^{2}$, Massimo Sanchez ${ }^{5}$, Emanuela Massi ${ }^{1}$, Giuseppe Lamorte ${ }^{6}$, Maria Grazia Diodoro $^{7}$, Edoardo Pescarmona7, Emanuela Signori ${ }^{1,8}$, Graziano Pesole ${ }^{2,9}$, Angelo Luigi Vescovi ${ }^{6}$, Jesus Garcia-Foncillas ${ }^{10+}$ and Vito Michele Fazio ${ }^{1,11^{*+}}$ (D)

\begin{abstract}
EphB2 and EphA2 control stemness and differentiation in the intestinal mucosa, but the way they cooperate with the complex mechanisms underlying tumor heterogeneity and how they affect the therapeutic outcome in colorectal cancer (CRC) patients, remain unclear. MicroRNA (miRNA) expression profiling along with pathway analysis provide comprehensive information on the dysregulation of multiple crucial pathways in CRC.

Through a network-based approach founded on the characterization of progressive miRNAomes centered on EphA2/ EphB2 signaling during tumor development in the AOM/DSS murine model, we found a miRNA-dependent orchestration of EphB2-specific stem-like properties in earlier phases of colorectal tumorigenesis and the EphA2specific control of tumor progression in the latest CRC phases. Furthermore, two transcriptional signatures that are specifically dependent on the EphA2/EphB2 signaling pathways were identified, namely EphA2, miR-423-5p, CREB1, ADAMTS14, and EphB2, miR-31-5p, mir-31-3p, CRK, CXCL12, ARPC5, SRC.

EphA2- and EphB2-related signatures were validated for their expression and clinical value in 1663 CRC patients. In multivariate analysis, both signatures were predictive of survival and tumor progression.

The early dysregulation of miRs-31, as observed in the murine samples, was also confirmed on 49 human tissue samples including preneoplastic lesions and tumors. In light of these findings, miRs-31 emerged as novel potential drivers of CRC initiation.

Our study evidenced a miRNA-dependent orchestration of EphB2 stem-related networks at the onset and EphA2related cancer-progression networks in advanced stages of CRC evolution, suggesting new predictive biomarkers and potential therapeutic targets.
\end{abstract}

Keywords: Colorectal cancer, MicroRNA, EphA2 and EphB2, Cancer stem cells, Biomarkers

\footnotetext{
*Correspondence: mariangela.derobertis@gmail.com; fazio@unicampus.it; vmfazio@operapadrepio.it

†Jesus Garcia-Foncillas and Vito Michele Fazio contributed equally to this work. ${ }^{1}$ Laboratory of Molecular Medicine and Biotechnology, University Campus Bio-Medico of Rome, via Alvaro del Portillo 21, 00128 Rome, Italy Full list of author information is available at the end of the article
}

(c) The Author(s). 2018 Open Access This article is distributed under the terms of the Creative Commons Attribution 4.0 International License (http://creativecommons.org/licenses/by/4.0/), which permits unrestricted use, distribution, and reproduction in any medium, provided you give appropriate credit to the original author(s) and the source, provide a link to the Creative Commons license, and indicate if changes were made. The Creative Commons Public Domain Dedication waiver (http://creativecommons.org/publicdomain/zero/1.0/) applies to the data made available in this article, unless otherwise stated. 
EphA2 and EphB2 are tyrosine kinase receptors that are involved in complex biochemical mechanisms underlying tumor heterogeneity primarily by guiding the positioning of intestinal cells with distinct stemness or differentiation properties [1]. EphA2 $2_{\text {high }}$ cells are localized in the upper differentiated crypt region, while EphB2 is expressed in a decreasing gradient from the crypt base toward the upper cell compartment and corresponds to an intestinal stem cell (ISC) marker [2]. At the onset of colorectal cancer (CRC), early events trigger continuous stem-like selfrenewing state, giving rise to adenoma, while additional driver pathway alterations confer invasive behavior in advanced carcinoma [3]. EphA2 and EphB2 undergo progressive dysregulation in carcinogenesis that may resemble these different stages, so representing attractive druggable targets [4].

MicroRNA (miRNA) redundancy and the capacity of individual miRNAs to simultaneously regulate large cohorts of genes have shaped by evolution combinatorial miRNA-target networks that profoundly affect cellular properties, including the promotion of tumorigenic processes [5]. A network-based approach founded on the characterization of progressive miRNAomes centered on EphA2/EphB2 signaling during tumor development may unveil important regulatory networks and oncogenic targets.

Given that EphA2 and EphB2 have opposite distribution and roles along the intestinal crypt, we hypothesized that these receptors may influence alternative cell behaviors on initial or advanced CRC stages. Through an integrative translational approach (Additional File 1: Figure S1) and a miRNAome-guided pathway analysis, we defined two transcriptional signatures that are associated with EphB2 cells/early CRC phases and EphA2 cells/late CRC phases, with significant prognostic value.

\section{Results and discussion}

\section{Distinct miRNAs characterize progressive stages of CRC} development

Given the poorly foreseeable multiphase pattern of human CRC (hCRC) development, we used the wellcharacterized azoxymethane (AOM)/dextran sodium sulfate (DSS) murine model of sporadic CRC to obtain a predictable neoplastic evolution through the colorectal "Aberrant crypt foci (ACF)-microadenoma-adenomacarcinoma" sequence, where each phase was expected to most likely progress to the following one [6, 7] (Fig. 1a; Additional file 1: Figure S2).

Of 641 miRNAs analyzed by TaqMan Low-Density Array (TLDA), 121 miRNAs were differentially expressed in the four murine CRC phases relative to normal mucosa $(P<0.05)$ (Fig. 1b, c, and d; Additional file 1: Figures S3 and S4). We found that the AOM/DSS model not only recapitulates several genetic modifications of hCRC [6], but also showed the aberrant expression of miRNAs belonging to hCRC-related pathways. In particular, miR-135b, targeting $\mathrm{APC} / \beta$-catenin pathway [8], was up-regulated in murine adenoma $(P<0.05)$; let-7 family and miR-143, acting as tumor-suppressors in KRAS-driven CRC [9], were down-regulated already in ACF (let-7a, c, d, f $P<0.05$ ) and in microadenoma (miR-143 $P<0.005)$; miR-9 was downregulated in all the stages $(P<0.05)$, correlating with its tumor-suppressor function in hCRC by mediating invasion and metastasis [10] (Fig. 1c, d). More importantly, miR31-5p and miR-31-3p were the most up-regulated in the earliest phases $(P<0.05$ in ACF) (Fig. 1c, d), suggesting that these miRNAs may be involved in the CRC initiation.

\section{Distinct EphA2/EphB2-specific miRNAomes orchestrate cell proliferation/stemness/migration in progressive murine CRC stages}

Based on cytofluorimetric, immunohistochemical and molecular characterization (Additional file 2: Methods and Materials) of EphA2 $2_{\text {high/low }}$ and $\mathrm{EphB} 2_{\text {high/low }}$ cells isolated from murine adenocarcinoma and normal colon (Additional file 1: Figure S5), we ascertained that EphA2 and EphB2 mark murine tumor cell subpopulations bearing either a differentiated or a stem-like phenotype, respectively.

With this assumption, we performed a TLDA-based miRNA expression analysis to characterize miRNAomes related to EphA2 $2_{\text {high/low }}$ and EphB2 high/low $\mathrm{CRC}$ cells (Additional file 3: Tables S1, S2).

A list of 180 miRNAs was associated with EphA2 and CRC. Moreover, according to the EphB2 $2_{\text {high }}$ CRC cells well-accepted identity of putative CSCs [2], we found they were enriched with miRNAs dysregulated in colon CSCs, such as miR-137, miR-34a, miR-215, miR-328 and miR-203 $(P<0.0001)[11]$.

Figure 1e describes a functional enrichment of the EphA2/EphB2 differential miRNAomes. All the functions analyzed were principally under control of miRNA targets listed in Additional file 3: Table S3.

When compared with the miRNAomes of murine ACF, microadenoma, adenoma and adenocarcinoma, the EphA2 and EphB2 tumor cells' miRNAomes resulted in the alternate control of specific functions in different CRC stages (Fig. 1f; Additional file 3: Table S4).

It is worth noting that functions concerning cell morphology/cell differentiation and the inactivation of cell proliferation and cell survival/death were exclusively associated with EphB2 and enriched in ACF. In contrast, cell survival/death and cell proliferation, cell migration and metastasis and the reduction of cell adhesion were significantly associated with EphA2 and enriched in adenoma and adenocarcinoma.

These results indicate that while ACF might be enriched with EphB2 high tumor-initiating cells, which exhibit 


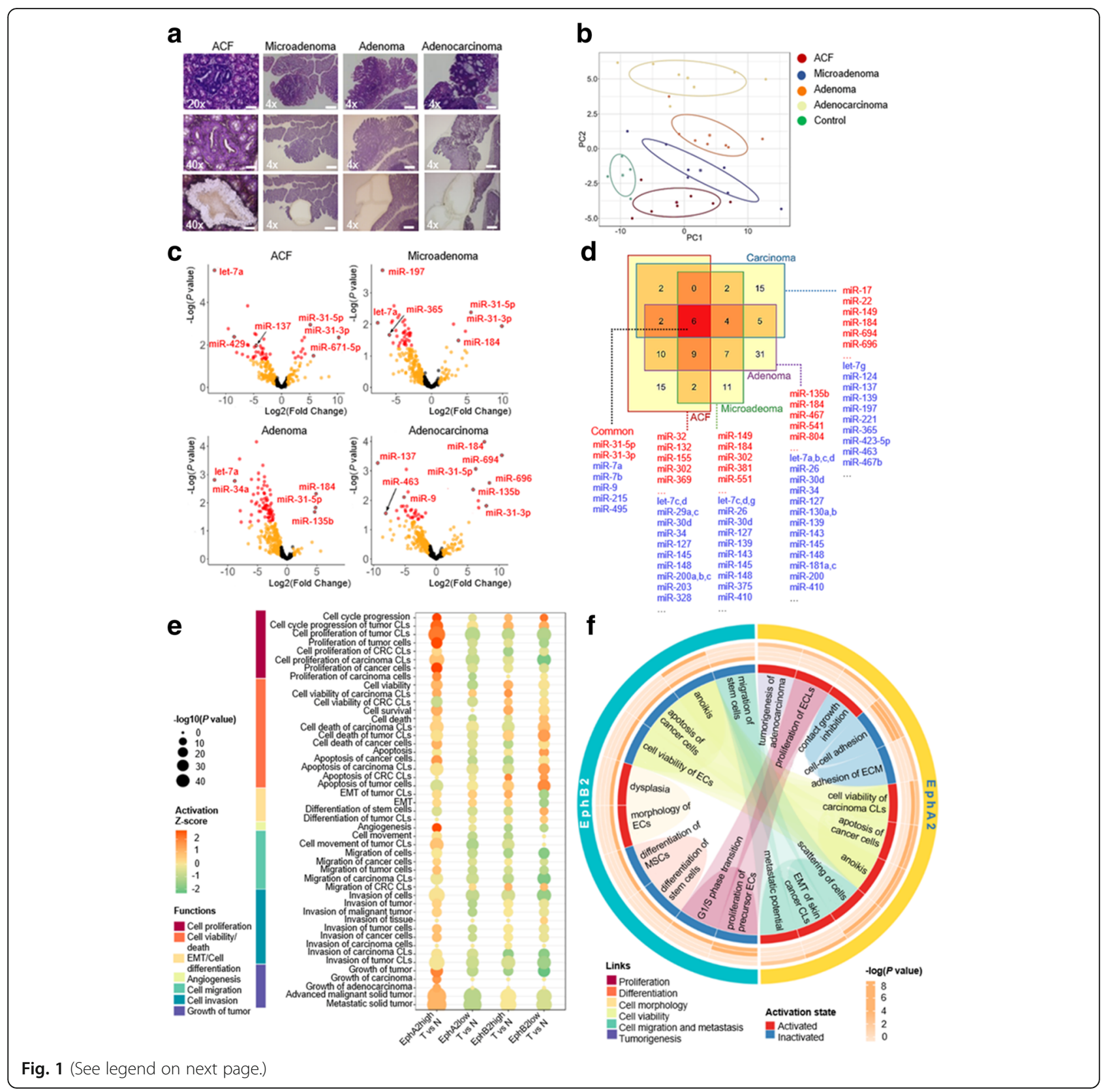


(See figure on previous page.)

Fig. 1 MiRNA expression profiling and functional enrichment analysis in progressive stages of murine CRC development: a Laser capture microdissection (LCM) of pretumoral lesions and tumors. First row, standard hematoxylin-eosin staining; second row, samples before LCM; third row, samples after LCM. Original magnification $\times 4$ (scale bar $200 \mu \mathrm{m}), \times 20$ (scale bar $50 \mu \mathrm{m}$ ), or $\times 40$ (scale bar $20 \mu \mathrm{m})$. b Clustering of phases and control samples based on the first two principal components (PC1 and PC2) in a p partial least square - discriminant analysis (sPLS-DA) model. Control: normal colon mucosa of untreated mice. $\mathbf{c}$ Volcano plots of differentially expressed (DE) miRNAs ( $P$ value $<0.05$ and |fold change $>2$ ) (red dots), miRNAs with only |fold change| $>$ 2 (orange dots), and other miRNAs (black dots). The results were obtained through comparisons between each phase and control samples. $\mathbf{d}$ Venn diagram representing the number of miRNAs altered in each phase and shared between different phases (numbers in Venn diagram) of CRC. Sets of wellknown CRC-associated miRNAs are indicated for each CRC phase (blue: down-regulated; red: up-regulated). e Enriched biological functions regulated by the DE miRNAs for Tumor (T) vs. Normal (N) of EphA2- and EphB2-positive cell comparisons. EphA2 high tumor cells are significantly enriched in activated functions related to cell proliferation, cell viability and cell death, angiogenesis, cell migration, cell invasion and growth of tumor $(P<0.0001)$. EphB2 high tumor cells show instead a significant enrichment of functions related to cell viability and a decreased or no activation of cell death/apoptosis $(P<0.0001)$. EMT activation and cell differentiation inactivation are also observed in EphB2 high tumor cells, a behavior coherently inverted in EphB2 low tumor cells $(P<0.0001)$. Sizes of bubbles are proportional to the statistical significance of the enriched functions (Fisher's exact test). Gradients of color vary from red (activation) to green (inhibition) according to the Z-scores calculated for each enriched function and for each comparison. Functions are grouped into macro-categories. f Biological functions regulated by the DE miRNAs (and their target genes) with concordant fold changes between EphB2 high cells and tissues and EphA2 high cells and tissues. The outer circle marks the biological functions that are enriched in the EphA2 high and EphB2 ${ }_{\text {high }}$ cells. The heatmap represents $-\log (P$ value) for each biological function evaluated in the four tissue types of adenocarcinoma (outer), adenoma, microadenoma, and ACF (inner). Blue and red rectangles represent the predicted activation and inactivation, respectively, of biological functions. These rectangles are linked by colored edges according to the macro-categories they belong to (proliferation, differentiation, cell morphology, etc.). Statistical significance was calculated using Fisher's exact test as implemented in IPA. Abbreviations: CLs, cell lines; CRC, colorectal cancer; ECs, epithelial cells; ECLs, EC lines; ECM, extracellular matrix; EMT, epithelial-mesenchymal transition; MSCs, mesenchymal stem cells

driver-gene/miRNA influencing CRC initiation via stemrelated functions, the latest stages of murine CRC show an enrichment with EphA2 high cells orchestrating functions primarily related to tumor malignancy.

\section{Establishment of two CRC EphA2/EphB2-specific signatures}

Considering the EphA2/EphB2 macro-pathway (Fig. 2a), we compared Eph pathway-related miRNAs included in our preclinical results to those dysregulated in CRC patients (The Cancer Genome Atlas - colon adenocarcinoma, TCGA-COAD). Eight miRNAs were concordantly dysregulated in both murine and human CRC (Fig. 2b). Strikingly, among them, miR-31-5p and miR-31-3p were up-regulated in all four murine CRC stages and in the

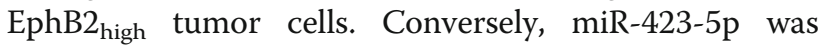
down-regulated in the advanced murine CRC phases and in the EphA2 high tumor cells. These miRNAs displayed inverse regulation in the two cell subpopulations (Fig. 2b), supporting the strong association of miRs-31 and miR-423-5p not only with specific CRC phases but also with specific Eph receptor-expressing cells.

The pathway analysis of 617 genes target of miRs-31 and miR-423-5p (Additional file 3: Tables S5 and S6) resulted to significantly enrich CRC-related signaling pathways ( $P$ value $<0.05)$ (Additional file 1: Figures S6 and S7).

On that basis, we defined two EphA2-/EphB2-related signatures by the combination of miRs-31 and miR-423-5p with their experimentally validated target genes belonging to the EphA2/EphB2 macro-pathway. Therefore, the EphB2 signature comprehended miRs-31, ROHA, CRKL, CRK, ITGA5, CXCL12, ARPC5, RASA1 and SRC, while the
EphA2 signature was composed of miR-423-5p, ARPC1A, PAK1, GNG12, CREB1 and ADAMTS14.

\section{Up-regulation of miRs-31 occurs at very early stages of hCRC development}

Given the importance of the early dysregulation of both miR-31-5p and miR-31-3p in the murine CRC, for their possible involvement in driving tumor initiation, we focused on the validation of their expression levels in the earliest stages of hCRC. We used a selected set of 49 human samples including low dysplasia (LD)-adenoma $(n=14)$, severe dysplasia (SD)-adenoma $(n=10)$, adenocarcinoma $(n=13)$ and normal mucosa $(n=12)$, that are not available in public datasets. qPCR analysis confirmed a significant overexpression of both miRs-31 in all the samples with an upward trend from LD-adenoma (preneoplastic) to SD-adenoma and adenocarcinoma, relative to normal mucosa (Student's $t$-test, $P<0.05$ ) (Fig. 2c). This is in line with recent demonstrations of miR-31-5p acting as a master modulator of the ISCs niche signaling during normal homeostasis, regeneration and tumorigenesis [12] or as potential driver of lung cancer initiation via KRAS pathway [13].

\section{Prognostic value of EphA2/EphB2-specific signatures}

Both EphA2 and EphB2 signatures were validated in 1663 CRC patients from nine cohorts of TCGA-COAD and Gene Expression Omnibus (GEO) databases, through a differential expression analysis between tumor and normal samples (Additional file 3: Table S7; Table 1a). EPHA2 was overexpressed in different datasets $(P<0.02)$ and miR-423-5p was concomitantly down-regulated $(P<0.01)$, whereas CREB1 and ADAMTS14 were overexpressed 


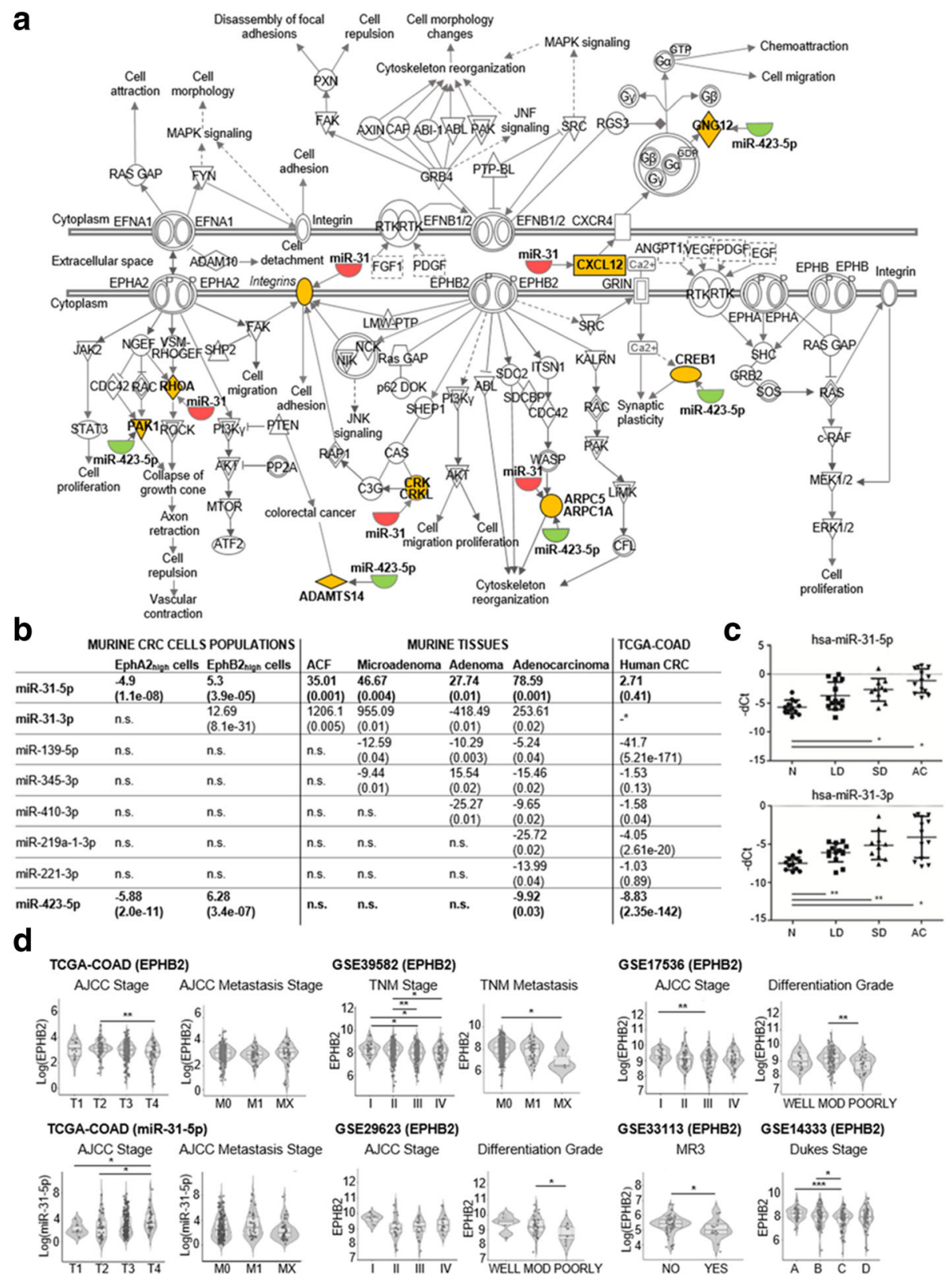

Fig. 2 a Scheme of a macro-pathway including both the EphA2 and EphB2 pathways with their cross-talk links. Down-regulated and upregulated miRNAs (miRs-31 and miR-423-5p) and their mRNA targets are colored in green, red and yellow respectively. b Summary table of Fold Change data with correlated $P$ values shown in brackets of 8 Eph pathway-related miRNAs concordantly DE in human CRC (TCGA-COAD) and in both EphA2 or EphB2 murine CRC cells. In bold the miRNAs concordantly DE in hCRC and in both murine EphA2/EphB2 cells and tissues. ${ }^{*}$ no -3p and $-5 p$ specification in miRNA nomenclature. Abbreviations: n.S., not significant. c qPCR analysis of miR-31-5p and miR-31-3p expression in normal colon mucosa (N), colorectal adenoma with low dysplasia (LD), colorectal adenoma with high dysplasia (HD), and adenocarcinoma (AC) human samples. Data are represented as the means +/- standard deviation (SD). Data are normalized by geometric mean of RNU48 and RNU6B. Statistically significant differences were calculated using Student's $t$-test. ${ }^{*} P<0.05,{ }^{* *} P<0.01$. d EphB2 and miR-31-5p analysis on hCRC staging progression (AJCC stage, TNM stage, Dukes stage), metastasis, and differentiation grade. Dots indicate individual data points, and their distribution is represented by violin and box plots. The box plots show the interquartile range and median value of the distribution. Abbreviations: $F C$, fold change; MOD, moderately differentiated; MR3, metastasis or recurrence within 3 years. ${ }^{*} P<0.05$; ${ }^{* *} P<0.01$ and ${ }^{* * *} P<0.001$; Mann-Whitney-U test

$(P<0.05)$. However, no significant changes in the expression levels of both EPHA2 and miR-423-5p were observed when they were analyzed in correlation with tumor staging progression (Additional file 1: Figure S8). EPHB2 was significantly overexpressed in TCGA-COAD $(P=0.03)$, GSE35834 cohort $(P=0.0008)$ and in patients with colorectal adenoma of GSE4183 cohort $(P<0.001)$; miR-31-5p was also overexpressed $(P<0.03)$ and its targets $C R K$, 
Table 1 Validation of the EphA2 and EphB2 signatures in GEO and TCGA-COAD public databases

a.

\begin{tabular}{|c|c|c|c|c|c|c|}
\hline & GSE35982 & GSE35834 & TCGA-COAD & GSE4183 & & \\
\hline & & & & $\begin{array}{l}\text { Adenoma } \\
\text { FC ( } P \text { value })\end{array}$ & $\begin{array}{l}\text { Carcinoma } \\
\text { FC ( } P \text { value })\end{array}$ & $\begin{array}{l}\text { IBD } \\
\text { FC ( } P \text { value })\end{array}$ \\
\hline EPHA2 & $\begin{array}{l}-1.16 \\
(0.35)\end{array}$ & $\begin{array}{l}1.18 \\
(0.02)\end{array}$ & $\begin{array}{l}1.27 \\
(0.40)\end{array}$ & $\begin{array}{l}1.7 \\
(0.07)\end{array}$ & $\begin{array}{l}1.67 \\
(0.08)\end{array}$ & $\begin{array}{l}2.16 \\
(0.003)\end{array}$ \\
\hline miR-423-5p & $\begin{array}{l}-2.2 \\
(0.30)\end{array}$ & $\begin{array}{l}-1.26 \\
(0.09)\end{array}$ & $\begin{array}{l}-8.82 \\
(2.35 e-142)\end{array}$ & - & - & - \\
\hline ARPC1A & $\begin{array}{l}-1.07 \\
(0.20)\end{array}$ & $\begin{array}{l}1.12 \\
(0.17)\end{array}$ & $\begin{array}{l}-1.09 \\
(0.35)\end{array}$ & $\begin{array}{l}1.14 \\
(0.32)\end{array}$ & $\begin{array}{l}1.16 \\
(0.24)\end{array}$ & $\begin{array}{l}-1.13 \\
(0.39)\end{array}$ \\
\hline PAK1 & $\begin{array}{l}-1.01 \\
(0.94)\end{array}$ & $\begin{array}{l}-1.07 \\
(0.25)\end{array}$ & $\begin{array}{l}-1.21 \\
(0.01)\end{array}$ & $\begin{array}{l}-1.27 \\
(0.02)\end{array}$ & $\begin{array}{l}-1.49 \\
(0.0006)\end{array}$ & $\begin{array}{l}-1.63 \\
(7.42 \mathrm{e}-05)\end{array}$ \\
\hline GNG12 & $\begin{array}{l}1.11 \\
(0.46)\end{array}$ & $\begin{array}{l}-1.63 \\
(2.48 \mathrm{e}-08)\end{array}$ & $\begin{array}{l}-1 \\
(0.128)\end{array}$ & $\begin{array}{l}-1.44 \\
(0.005)\end{array}$ & $\begin{array}{l}-1.28 \\
(0.04)\end{array}$ & $\begin{array}{l}-1.35 \\
(0.02)\end{array}$ \\
\hline CREB1 & $\begin{array}{l}-1.06 \\
(0.40)\end{array}$ & $\begin{array}{l}-1.04 \\
(0.38)\end{array}$ & $\begin{array}{l}2.72 \\
(2.85 e-34)\end{array}$ & $\begin{array}{l}1.16 \\
(0.15)\end{array}$ & $\begin{array}{l}1.36 \\
(0.005)\end{array}$ & $\begin{array}{l}1.26 \\
(0.04)\end{array}$ \\
\hline ADAMTS14 & $\begin{array}{l}-1.03 \\
(0.67)\end{array}$ & $\begin{array}{l}1.03 \\
(0.52)\end{array}$ & $\begin{array}{l}2.81 \\
(0.0003)\end{array}$ & $\begin{array}{l}-1.05 \\
(0.85)\end{array}$ & $\begin{array}{l}1.32 \\
(0.21)\end{array}$ & $\begin{array}{l}1.52 \\
(0.05)\end{array}$ \\
\hline EPHB2 & $\begin{array}{l}1.19 \\
(0.49)\end{array}$ & $\begin{array}{l}1.33 \\
(0.0008)\end{array}$ & $\begin{array}{l}1.75 \\
(0.03)\end{array}$ & $\begin{array}{l}3.39 \\
(7.75 e-06)\end{array}$ & $\begin{array}{l}1.26 \\
(0.16)\end{array}$ & $\begin{array}{l}-1.13 \\
(0.67)\end{array}$ \\
\hline$m i R-31-5 p$ & $\begin{array}{l}49.65 \\
(0.02)\end{array}$ & $\begin{array}{l}3.17 \\
(0.03)\end{array}$ & $\begin{array}{l}2.71 \\
(0.41)\end{array}$ & - & - & - \\
\hline miR-31-3p & $\begin{array}{l}14.73 \\
(0.005)\end{array}$ & - & - & - & - & - \\
\hline $\mathrm{RHOA}$ & $\begin{array}{l}1.10 \\
(0.08)\end{array}$ & $\begin{array}{l}-1.01 \\
(0.71)\end{array}$ & $\begin{array}{l}-1.08 \\
(0.28)\end{array}$ & $\begin{array}{l}1.12 \\
(0.06)\end{array}$ & $\begin{array}{l}-1.29 \\
(0.21)\end{array}$ & $\begin{array}{l}1.09 \\
(0.13)\end{array}$ \\
\hline CRKL & $\begin{array}{l}1.07 \\
(0.54)\end{array}$ & $\begin{array}{l}1.12 \\
(0.002)\end{array}$ & $\begin{array}{l}1.18 \\
(0.03)\end{array}$ & $\begin{array}{l}1.20 \\
(0.139)\end{array}$ & $\begin{array}{l}1.13 \\
(0.14)\end{array}$ & $\begin{array}{l}-1.19 \\
(0.22)\end{array}$ \\
\hline CRK & $\begin{array}{l}-1.11 \\
(0.36)\end{array}$ & $\begin{array}{l}-1.25 \\
(0.0008)\end{array}$ & $\begin{array}{l}-1.12 \\
(0.10)\end{array}$ & $\begin{array}{l}-1.22 \\
(0.02)\end{array}$ & $\begin{array}{l}-1.15 \\
(0.09)\end{array}$ & $\begin{array}{l}-1.13 \\
(0.12)\end{array}$ \\
\hline ITGA5 & $\begin{array}{l}1.78 \\
(0.30)\end{array}$ & $\begin{array}{l}-1.08 \\
(0.38)\end{array}$ & $\begin{array}{l}-1.13 \\
(0.64)\end{array}$ & $\begin{array}{l}1.88 \\
(0.59)\end{array}$ & $\begin{array}{l}4.50 \\
(0.03)\end{array}$ & $\begin{array}{l}4.56 \\
(0.03)\end{array}$ \\
\hline CXCL12 & $\begin{array}{l}-1.19 \\
(0.69)\end{array}$ & $\begin{array}{l}-2.40 \\
(9.44 \mathrm{e}-14)\end{array}$ & $\begin{array}{l}-3.00 \\
(6.55 e-18)\end{array}$ & $\begin{array}{l}-6.91 \\
(9.80 \mathrm{E}-09)\end{array}$ & $\begin{array}{l}-2.90 \\
(2.95 \mathrm{E}-06)\end{array}$ & $\begin{array}{l}-1.48 \\
(0.01)\end{array}$ \\
\hline ARPC5 & $\begin{array}{l}-1.18 \\
(0.05)\end{array}$ & $\begin{array}{l}1.01 \\
(0.62)\end{array}$ & $\begin{array}{l}1.09 \\
(0.36)\end{array}$ & $\begin{array}{l}-1.33 \\
(0.06)\end{array}$ & $\begin{array}{l}-1.36 \\
(0.05)\end{array}$ & $\begin{array}{l}-1.37 \\
(0.05)\end{array}$ \\
\hline RASA1 & $\begin{array}{l}-1.03 \\
(0.61)\end{array}$ & $\begin{array}{l}1.19 \\
(0.04)\end{array}$ & $\begin{array}{l}2.60 \\
(1.92 \mathrm{e}-20)\end{array}$ & $\begin{array}{l}1.21 \\
(0.02)\end{array}$ & $\begin{array}{l}1.11 \\
(0.23)\end{array}$ & $\begin{array}{l}-1.10 \\
(0.30)\end{array}$ \\
\hline SRC & $\begin{array}{l}1.23 \\
(0.16)\end{array}$ & $\begin{array}{l}1.20 \\
(0.0008)\end{array}$ & $\begin{array}{l}-1.37 \\
(0.02)\end{array}$ & $\begin{array}{l}-1.37 \\
(0.10)\end{array}$ & $\begin{array}{l}-1.57 \\
(0.03)\end{array}$ & $\begin{array}{l}1.79 \\
(0.03)\end{array}$ \\
\hline
\end{tabular}

b.

Multivariate analysis of EPHA2 genetic signature without hsa-miR-423-5p

$\begin{array}{llll} & \text { Relative Risk } & \mathbf{9 5 \%} \mathbf{C l} & \boldsymbol{P} \text { value } \\ \begin{array}{l}\text { TCGA-COAD (OS) } \\ \text { ADAMTS14 }\end{array} & 1.07 & 0.97 \text { to } 1.19 & 0.17 \\ \text { CREB1 } & 0.97 & 0.87 \text { to } 1.09 & 0.65 \\ \begin{array}{l}\text { GSE33113 (MR3) } \\ \text { ADAMTS14 }\end{array} & & 0.99 \text { to } 1.06 & \mathbf{0 . 0 5} \\ \text { CREB1 } & 1.03 & 0.99 \text { to } 1.03 & 0.44 \\ \text { GSE14333 (DFS) } & 1.01 & & \mathbf{0 . 0 0 1} \\ \text { ADAMTS14 } & & 0.65 \text { to } 0.90 & 0.99 \\ \text { CREB1 } & 0.76 & 0.54 \text { to } 1.84 & \end{array}$


Table 1 Validation of the EphA2 and EphB2 signatures in GEO and TCGA-COAD public databases (Continued)

\section{GSE17536 (OS)}

ADAMTS14 0.79

CREB1

\subsection{9}

1.43

GSE29623 (OS)

$\begin{array}{ll}\text { ADAMTS14 } & 0.36 \\ \text { CREB1 } & 0.82\end{array}$

Multivariate analysis of EPHB2 genetic signature without hsa-miR-31-5p

\section{TCGA-COAD (OS)}

$\begin{array}{ll}\text { CRK } & 0.97 \\ \text { CXCL12 } & 1.03 \\ \text { ARPC5 } & 0.99 \\ \text { SRC } & 1.00\end{array}$

\section{Relative Risk}

0.97

1.03

0.99

1.00

GSE33113 (MR3)

CRK

1.01

CXCL12

1.00

ARPC5

1.00

SRC

1.00

GSE14333 (DFS)

$\begin{array}{ll}\text { CRK } & 0.80 \\ \text { CXCL12 } & 0.74 \\ \text { ARPC5 } & 0.8 \\ \text { SRC } & 1.08\end{array}$

GSE17536 (OS)

CRK 1.14

$\begin{array}{ll}\text { CXCL12 } & 0.98\end{array}$

ARPC5 1.27

SRC $\quad 0.10$

GSE29623 (OS)

CRK 0.83

$\begin{array}{lll}\mathrm{CXCL} 12 & 1.02\end{array}$

ARPC5 $\quad 0.25$

SRC

0.09

Multivariate analysis of EPHA2 genetic signature with hsa-miR-423-5p

\section{Relative Risk}

0.54 to 1.20

0.60 to 0.92

0.50 to 1.30

0.79 to 1.48

0.49 to 2.66

0.69 to 1.39

0.37 to 4.35

0.02 to 0.54

0.15 to 4.52

0.45 to 2.32

0.03 to 2.03

0.002 to 4.13

0.69

0.44

0.36

0.83

\section{$P$ value}

0.15

0.17

0.53

0.79

0.01

0.02

0.05

0.95

0.29

0.01

0.38

0.63

0.75

0.90

0.70

0.01

TCGA-COAD (OS)

ADAMTS14

1.07

CREB1

hsa-miR-423-5p

1.00

GSE 29623 (OS)

ADAMTS14

CREB1
$95 \% \mathrm{Cl}$

$\begin{array}{ll}0.97 \text { to } 1.18 & 0.18 \\ 0.87 \text { to } 1.1009 & 0.67 \\ 0.99 \text { to } 1.00 & 0.69\end{array}$

0.04 to 3.02

0.13 to 5.12

0.34

0.71 to 1.52

0.85 
Table 1 Validation of the EphA2 and EphB2 signatures in GEO and TCGA-COAD public databases (Continued)

\begin{tabular}{|c|c|c|c|}
\hline \multicolumn{4}{|c|}{ Multivariate analysis of EPHB2 genetic signature with hsa-miR-31-5p } \\
\hline & Relative Risk & $95 \% \mathrm{Cl}$ & $P$ value \\
\hline \multicolumn{4}{|l|}{ TCGA-COAD (OS) } \\
\hline CRK & 0.97 & 0.93 to 1.01 & 0.11 \\
\hline CXCL12 & 1.03 & 0.99 to 1.07 & 0.10 \\
\hline ARPC5 & 0.99 & 0.97 to 1.02 & 0.65 \\
\hline SRC & 1.00 & 0.98 to 1.03 & 0.90 \\
\hline hsa-miR-31-5p & 1.00 & 1.00 to 1.01 & 0.001 \\
\hline \multicolumn{4}{|l|}{ GSE29623 (OS) } \\
\hline CRK & 0.69 & 0.12 to 3.81 & 0.67 \\
\hline CXCL12 & 1.31 & 0.53 to 3.21 & 0.56 \\
\hline ARPC5 & 0.28 & 0.04 to 2.23 & 0.23 \\
\hline SRC & 0.12 & 0.003 to 4.88 & 0.26 \\
\hline hsa-miR-31-5p & 1.17 & 0.95 to 1.46 & 0.14 \\
\hline
\end{tabular}

CXCL12, ARPC5 and SRC were down-regulated in three out of six cohorts. It is worth noting that in the analysis of the GSE4183 cohort, the expression level of EphB2 decreased in the transition from adenoma to carcinoma. In line with this observation, we found that EPHB2 expression levels gradually decreased with the progression of the TNM/AJCC stage and with metastasis (Fig. 2d). These results support the model that during CRC progression, stem EphB2-dependent functions are confined to a very small cell fraction of the tumor mass [7, 14], which likely represents the tumorigenic cell reservoir. Moreover, a gradual increase of miR-31-5p expression levels was observed with the progression of the TNM/AJCC stage (Fig. 2d), suggesting that it could be associated not only with particular miRNA patterns of stem-like EphB2 $2_{\text {high }}$ cells during tumorigenesis, but also with miRNA patterns of different cell populations replenishing the tumor mass in progressive CRC stages. Our findings are in line with functional studies showing that miR-31 has pleiotropic activity and is typically overexpressed with high expression correlating with advanced CRC disease [15].

In addition, we evaluated the collective prognostic effect of the EphA2 and EphB2 signatures (multivariate Cox-regression analysis) (Table 1b). Regarding the EphA2 fingerprint, $A D A M T S 14$ was a risk factor for disease-free survival (DFS) $(P<0.001)$ and metastasis or recurrence within 3 years (MR3) $(P<0.05)$. Concerning the EphB2 fingerprint, $S R C$ was a risk factor for overall survival (OS) $(P<0.01), C X C L 12$ was significant for DFS $(P<0.01), C R K, C X C L 12$ and $A R P C 5$ were significant for MR3 $(P<0.05)$. Furthermore, miR-31-5p was deemed a risk factor in TCGA-COAD $(P<0.001)$. Our results confirm the involvement of these molecules in a complex network affected by EphA2/EphB2 signaling pathways and their crosstalk.

\section{Conclusions}

EphA2 and EphB2 contribute, in a pleiotropic manner, to the CRC pathogenesis. We demonstrated that the early dysregulation of EphB2 at the CRC onset correlates with specific stem-like properties and that the late overexpression of EphA2 triggers tumor progression signals in the invasive CRC phase. These properties are orchestrated by distinct miRNAomes and are associated with miR-31-5p/miR-31-3p, miR-423-5p and their EphA2/ EphB2-related target genes. These signatures have significant clinical value and may unveil clinical predictive biomarkers and potential therapeutic markers.

\section{Additional files}

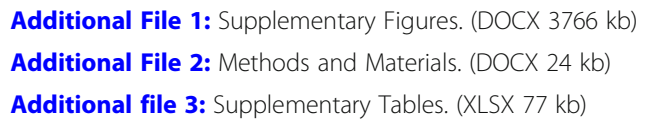

\section{Abbreviations}

ACF: Aberrant crypt foci; AOM: Azoxymethane; CRC: Colorectal cancer; CSCs: Cancer stem cells; DFS: Disease-free survival; DSS: Dextran sodium sulfate; GEO: Gene Expression Omnibus; ISCs: Intestinal stem cells; LD: Low dysplasia; miRNAs: microRNAs; MR3: Metastasis or recurrence within 3 years; OS: Overall survival; SD: Severe dysplasia; TCGA-COAD: The Cancer Genome Atlas - colon adenocarcinoma; TLDA: TaqMan Low-Density Array

\section{Acknowledgements}

Not applicable.

\section{Funding}

This work was partially supported by grants from Italian Ministry of

Education, University and Research (MIUR) national research program: MIUR 
RBAP10KJC5 to ALV, MIUR PON02_00576_3329762/3 AMIDERHA to VMF, and MIUR PON03PE 00232 Distretto H-Bio to VMF and GP, and Italian Association for Cancer Research: AIRC IG 14368 to ALV and AIRC MFAG 10520 to MLP. This work was also partially supported by the Italian Ministry of Health, IRCCS Ricerca Corrente RC1803LO36 to VMF. Bioinformatics analyses carried out by GP were performed using the infrastructures of the Italian node of ELIXIR funded by MIUR and Consiglio Nazionale delle Ricerche (CNR).

\section{Availability of data and materials}

The authors declare that the data supporting the findings of this study are available within the article and its supplementary information files.

\section{Authors' contributions}

VMF conceived and oversaw the project. MDR designed and performed all the experiments, including the animal experiments, the laser capture microdissection, the immunohistochemistry and the molecular analyses. TM and CF performed all the bioinformatics and statistical analyses. GP contributed with IPA analysis. JGF oversaw laser capture microdissection, miRNA profiling and contributed to project conceiving. ES oversaw the animal experiments. MDR, LL, MLP and EM contributed to the molecular analyses. MS and GL performed the cell biology experiments and cytofluorimetric analysis. MGD and EP collected the tissue samples of CRC patients and performed histological analyses. VMF and MDR interpreted data and wrote the manuscript. TM, CF, MLP, GP, ES, JGF and ALV discussed the results and assisted in revisions. All authors read and approved the final manuscript

\section{Ethics approval and consent to participate}

Use and treatment of mice was approved by the Italian Ministry of Health with decree no. 336/2013-B.

The collection of clinical samples was approved by the Ethics Committee of the IRCCS "Regina Elena" National Cancer Institute and all patients signed an informed consent in accordance with the WMA Declaration of Helsinki 2013.

\section{Consent for publication}

Not applicable.

\section{Competing interests}

All authors declare that they have no competing interest.

\section{Publisher's Note}

Springer Nature remains neutral with regard to jurisdictional claims in published maps and institutional affiliations.

\begin{abstract}
Author details
${ }^{1}$ Laboratory of Molecular Medicine and Biotechnology, University Campus Bio-Medico of Rome, via Alvaro del Portillo 21, 00128 Rome, Italy. ${ }^{2}$ Department of Biosciences, Biotechnology and Biopharmaceutics, University of Bari "A. Moro", via Orabona 4, 70126 Bari, Italy. ${ }^{3}$ Fondazione IRCCS Casa Sollievo della Sofferenza, Bioinformatics Unit, viale dei Cappuccini, 71013 San Giovanni Rotondo, FG, Italy. ${ }^{4}$ New Drug Modalities, Drug Safety and Metabolism, AstraZeneca iMED Biotech Unit, Cambridge, UK. ${ }^{5}$ Core Facilities Cytometry unit, Istituto Superiore di Sanità, Viale Regina Elena 299, 00161 Rome, Italy. ${ }^{6}$ Fondazione IRCCS Casa Sollievo della Sofferenza, viale dei Cappuccini, 71013 San Giovanni Rotondo, FG, Italy. ${ }^{7}$ Department of Pathology, IRCCS "Regina Elena", National Cancer Institute, Via E. Chianesi 53, 00144 Rome, Italy. ${ }^{8}$ Laboratory of Molecular Pathology and Experimental Oncology, Institute of Translational Pharmacology, Consiglio Nazionale delle Ricerche (CNR), Via Fosso del Cavaliere 100, 00133 Rome, Italy. ${ }^{9}$ Institute of Biomembranes, Bioenergetics and Molecular Biotechnologies, Consiglio Nazionale delle Ricerche (CNR), Via Amendola 165/A, 70126 Bari, Italy. ${ }^{10}$ Cancer Institute, University Hospital "Fundacion Jimenez Diaz", Autonomous University, Av. Reyes Catolicos 2, 28040 Madrid, Spain. ${ }^{11}$ Fondazione IRCCS Casa Sollievo della Sofferenza, Laboratory of Oncology, viale dei Cappuccini, 71013 San Giovanni Rotondo, FG, Italy.
\end{abstract}

Received: 28 June 2018 Accepted: 6 November 2018

Published online: 30 November 2018

\section{References}

1. Kania A, Klein R. Mechanisms of ephrin-Eph signalling in development, physiology and disease. Nat Rev Mol Cell Biol. 2016;17:240-56.
2. Merlos-Suárez A, Barriga FM, Jung P, Iglesias M, Céspedes MV, Rossell D, et al. The intestinal stem cell signature identifies colorectal cancer stem cells and predicts disease relapse. Cell Stem Cell. 2011;8:511-24.

3. Tauriello DVF, Calon A, Lonardo E, Batlle E. Determinants of metastatic competency in colorectal cancer. Mol Oncol. 2017;11:97-119.

4. Lodola A, Giorgio C, Incerti M, Zanotti I, Tognolini M. Targeting Eph/ephrin system in cancer therapy. Eur J Med Chem. 2017;142:152-62.

5. Bracken CP, Scott HS, Goodall GJ. A network-biology perspective of microRNA function and dysfunction in cancer. Nat Rev Genetics. 2016;17:719-32.

6. De Robertis M, Massi E, Poeta ML, Carotti S, Morini S, Cecchetelli L, et al. The AOM/DSS murine model for the study of colon carcinogenesis: from pathways to diagnosis and therapy studies. J Carcinog. 2011;10:9.

7. De Robertis M, Loiacono L, Fusilli C, Poeta ML, Mazza T, Sanchez M, et al. Dysregulation of EGFR pathway in EphA2 cell subpopulation significantly associates with poor prognosis in colorectal Cancer. Clin Cancer Res. 2017; 23:159-70.

8. Nagel R, le Sage C, Diosdado B, van der Waal M, Oude Vrielink JA, Bolijn A, et al. Regulation of the adenomatous polyposis coli gene by the miR-135 family in colorectal cancer. Cancer Res. 2008;68:5795-802.

9. Kent OA, Chivukula RR, Mullendore M, et al. Repression of the miR-143/145 cluster by oncogenic Ras initiates a tumor-promoting feed-forward pathway. Genes Dev. 2010;24:2754-9.

10. Park YR, Lee ST, Kim SL, Liu YC, Lee MR, Shin JH, et al. MicroRNA-9 suppresses cell migration and invasion through downregulation of TM4SF1 in colorectal cancer. Int J Oncol. 2016;48:2135-43.

11. De Robertis M, Poeta ML, Signori E, Fazio VM. Current understanding and clinical utility of miRNAs regulation of colon cancer stem cells. Semin Cancer Biol. 2018. https://doi.org/10.1016/j.semcancer.2018.08.008. [Epub ahead of print].

12. Tian Y, Ma X, Lv C, Sheng X, Li X, Zhao R, et al. Stress responsive miR-31 is a major modulator of mouse intestinal stem cells during regeneration and tumorigenesis. Elife. 2017;6:e29538. https://doi.org/10.7554/eLife.29538.

13. Edmonds MD, Boyd KL, Moyo T, Mitra R, Duszynski R, Arrate MP, et al. MicroRNA-31 initiates lung tumorigenesis and promotes mutant KRASdriven lung cancer. J Clin Invest. 2016;126:349-64.

14. Zeuner A, Todaro M, Stassi G, De Maria R. Colorectal cancer stem cells: from the crypt to the clinic. Cell Stem Cell. 2014;15:692-705.

15. Schee K, Boye K, Abrahamsen TW, Fodstad O, Flatmark K. Clinical relevance of microRNA miR-21, miR-31, miR-92a, miR-101, miR-106a and miR-145 in colorectal cancer. BMC Cancer. 2012;12:505.
Ready to submit your research? Choose BMC and benefit from:
- fast, convenient online submission
- thorough peer review by experienced researchers in your field
- rapid publication on acceptance
- support for research data, including large and complex data types
- gold Open Access which fosters wider collaboration and increased citations
- maximum visibility for your research: over $100 \mathrm{M}$ website views per year
At BMC, research is always in progress.
Learn more biomedcentral.com/submissions 